\title{
Genetic parameters of meat quality, carcass composition, and growth traits in commercial swine
}

\author{
Piush Khanal, ${ }^{\dagger, 1}$ Christian Maltecca, ${ }^{\dagger}$ Clint Schwab, ${ }^{\ddagger}$ Kent Gray, ${ }^{\Perp}$ and Francesco Tiezzi ${ }^{\dagger}$ \\ 'Department of Animal Science, North Carolina State University, Raleigh, NC 27695; ${ }^{*}$ The Maschhoffs LLC, \\ Carlyle, IL 62231; and "Smithfield Premium Genetics, Rose Hill, NC 28458
}

\begin{abstract}
Swine industry breeding goals are mostly directed towards meat quality and carcass traits due to their high economic value. Yet, studies on meat quality and carcass traits including both phenotypic and genotypic information remain limited, particularly in commercial crossbred swine. The objectives of this study were to estimate the heritabilities for different carcass composition traits and meat quality traits and to estimate the genetic and phenotypic correlations between meat quality, carcass composition, and growth traits in 2 large commercial swine populations: The Maschhoffs LLC (TML) and Smithfield Premium Genetics (SPG), using genotypes and phenotypes data. The TML data set consists of 1,254 crossbred pigs genotyped with $60 \mathrm{~K}$ SNP chip and phenotyped for meat quality, carcass composition, and growth traits. The SPG population included over 35,000 crossbred pigs phenotyped for meat quality, carcass composition, and growth traits. For TML data sets, the model included fixed effects of dam line, contemporary group (CG), gender, as well as random additive genetic effect and pen nested within CG. For the SPG data set,
\end{abstract}

fixed effects included parity, gender, and CG, as well as random additive genetic effect and harvest group. Analyses were conducted using BLUPF90 suite of programs. Univariate and bivariate analyses were implemented to estimate heritabilities and correlations among traits. Primal yield traits were uniquely created in this study. Heritabilities [high posterior density interval] of meat quality traits ranged from $0.08[0.03,0.16]$ for $\mathrm{pH}$ and 0.08 $[0.03,0.1]$ for Minolta $b^{*}$ to $0.27[0.22,0.32]$ for marbling score, except intramuscular fat with the highest estimate of 0.52 [0.40, 0.62]. Heritabilities of primal yield traits were higher than that of primal weight traits and ranged from 0.17 [0.13, $0.25]$ for butt yield to $0.45[0.36,0.55]$ for ham yield. The genetic correlations of meat quality and carcass composition traits with growth traits ranged from moderate to high in both directions. High genetic correlations were observed for male and female for all traits except $\mathrm{pH}$. The genetic parameter estimates of this study indicate that a multitrait approach should be considered for selection programs aimed at meat quality and carcass composition in commercial swine populations.

Key words: carcass, genetic correlations, heritability, meat quality

(C) The Author(s) 2019. Published by Oxford University Press on behalf of the American Society of Animal Science. All rights reserved. For permissions, please e-mail: journals.permissions@oup.com.

J. Anim. Sci. 2019.97:3669-3683 doi: $10.1093 /$ jas/skz247

\section{INTRODUCTION}

The demand for higher quality meat by consumers has been steadily growing. Both meat quality and carcass composition traits are

${ }^{1}$ Corresponding author: pkhanal2@ncsu.edu

Received April 23, 2019.

Accepted July 23, 2019. becoming important in swine breeding programs because of their increased economic value (Dransfield et al., 2005). Until the recent past, producers were paid for the weight of carcass as opposed to the weight of each primal cut (Miar et al., 2014a). Now, the swine industry has focused its attention towards meat quality traits (Dransfield et al., 2005; Lattore et al., 2008), and producers are aiming at improving intramuscular 
fat, color, firmness, and different primal cuts (van Wijk et al., 2005; Miar et al., 2014a) to meet consumer demands.

Estimation of genetic parameters for pork quality traits and their correlations with carcass composition and production traits are necessary for successful breeding programs that focus on meat quality. Carcass composition traits exhibit moderate to high heritability, whereas meat quality traits exhibit low to moderate heritability (Ciobanu et al., 2011; Miar et al., 2014a). Hence, selection for meat quality traits is challenging and makes the use of genomic selection particularly appealing (Lee et al., 2015). Genomic selection provides more genetic gain per unit time by increasing selection accuracy without costly and time-consuming progeny testing (van der Werf, 2013). Previous studies on meat quality and carcass traits on purebred swine (Cameron et al., 1990; Gilbert et al., 2007; Cabling et al., 2015) and crossbred swine (Van Wijk et al., 2005; Miar et al., 2014a; Miar et al., 2014b) were conducted only with pedigree information. The results from these studies indicated a wide range of heritability and correlation estimates. Estimates of genetic parameters of meat quality and carcass composition traits which include both phenotypic and genotypic information remain limited, particularly in crossbred swine. The objectives of this study were, therefore, to estimate the heritabilities for different carcass composition traits and meat quality traits and to estimate the genetic and phenotypic correlations between the meat quality, carcass composition, and growth traits in 2 large commercial crossbred swine populations using genotypes and phenotypes data.

\section{MATERIALS AND METHODS}

Animal welfare approval was not needed for this study because recorded data came from animals raised in commercial facilities under routine circumstances. Pigs were slaughtered in commercial facilities under the supervision of USDA Food Safety and Inspection Service. Two large commercial crossbred swine populations: The Maschhoffs LLC and Smithfield Premium Genetics were available for this study and analyzed separately.

\section{The Maschhoffs LLC (TML)}

Animals. Data were collected from 1,254 terminal cross pigs raised in a commercial setting managed by The Maschhoffs LLC (Claryle, IL) and were obtained from the cross of 28 Duroc sires and 806 commercial $F_{1}$ sows composed of Yorkshire $\times$ Landrace or Landrace $\times$ Yorkshire sows. The weaned pigs $(n=6,642)$ were moved to 334 single-sex single-sire pens with approximately 20 pigs per pen. The experiment was repeated 6 times, each of which comprised of 2 pens (1 pen of female pig and 1 pen of castrated male pig). Pigs that came together in 1 replicate were put in 1 contemporary group. Five pigs were selected from each pen for the collection of detailed phenotypic data. The selected pigs represented a pig with BW 1 SD above and a pig with BW 1 SD below the average BW of the pen, a pig with BW 2 SD above and a pig with BW 2 SD below the average BW of the pen, and a pig with $\mathrm{BW}$ closest to the average $\mathrm{BW}$ of the pen. The 1,254 selected pigs were genotyped with the PorcineSNP60 v2 BeadChip (Illumina, Inc., San Diego, CA). Quality control procedures were applied by removing the SNPs that had call rate less than 0.90 and minor allele frequency less than 0.05 , respectively. The final number of SNPs after quality control was 42,529. The Duroc sires had pedigrees traced back for 9 generations, whereas no pedigree information was available for the $\mathrm{F}_{1}$ dams. Parity information was not available for the $F_{1}$ dams. Transportation of pigs to the slaughterhouse was done as detailed by Wilson et al. (2016). Pigs were slaughtered when the average body weight of each pen was $138 \mathrm{~kg}$. Pigs were immobilized via carbon dioxide stunning and killed by exsanguination.

Data collection. After the commercial slaughter procedures, fat depth (FD) and loin depth (LD) were measured using a Fat-O-Meater probe (SFK Technology A/S, Herlev, Denmark) at approximately 10th rib location before measurement of hot carcass weight $(\mathrm{HCW})$. Hot carcass weight was recorded immediately after animals were stunned, exsanguinated, and dressed. Carcasses were then split, and blast chilled for approximately $90 \mathrm{~min}$ and different meat quality and carcass traits were measured. Carcasses were separated at approximately $22 \mathrm{~h}$ postmortem into primal cuts, and different primal weights were measured: ham (HAM), butt (BUTT), picnic (PICN), sparerib (SRIB), total loin (LOIN1), and belly (BEL1) weight. Skin-on belly weight was recorded. The proportion of primal cuts, i.e., ham yield (HAMY), loin yield (LOINY1), belly yield (BELY1), sparerib yield (SRIBY), picnic yield (PICNY), and butt yield (BUTTY) were calculated by dividing the respective primal cut weight by HCW. The total primal yield (PRIMY) was calculated as the proportion of sum of all primal cuts to HCW. Carcass average daily gain (CADG) was 
calculated by dividing the difference of HCW and birth weight by the age when that pig was sent to market. Loins were separated from the shoulder between the second and third ribs and separated from the ham 2.79 to $3.81 \mathrm{~cm}$ anterior to symphysis pubis bone and made-up boneless, vacuum-packaged, and sent to the University of Illinois Meat Science Laboratory and preserved as described by Wilson et al. (2017).

Boneless loins were aged for $14 \mathrm{~d}$ postmortem at $4{ }^{\circ} \mathrm{C}$. After $14 \mathrm{~d}$, loins were removed from the packaging and measured for $\mathrm{pH}$, and mechanically sliced into $2.54 \mathrm{~cm}$ thick chops as described by Wilson et al. (2016). Ultimate $\mathrm{pH}$ (PH) was measured on the ventral side of the longissimus dorsi muscle using handheld MPI $\mathrm{pH}$-meter fitted with a glass electrode (Meat Probes Inc., Topeka, KS). After slicing, a minimum of $30 \mathrm{~min}$ was allowed for the oxygenation of myoglobin before the subjective measurements, and instrumental color measurements were recorded. The subjective color score (SCOL) and subjective marbling score (SMARB) were recorded on the basis of 5 color categories $(2.0,2.5,3.0,3.5$, and 4.0) and 6 marbling categories $(<1.5,2.0,2.5$, 3.0, 3.5, and >4.0) as reported by Wilson et al. (2017) where higher color score represents the darker chop and the higher marbling score represents the greater extractable lipid content of each chop. Subjective firmness score (SFIRM) was measured using the scale from 1 to 5 , where 1 was the softest and 5 was the firmest. Instrumental L* (MINL), a* (MINA), and $b^{*}$ (MINB) color scores measured the lightness (greater $\mathrm{L}^{*}$ indicates a lighter as opposed to darker color), redness (greater $\mathrm{a}^{*}$ indicates a more red color as opposed to green), and yellowness (greater $b^{*}$ indicates a more yellow color as opposed to blue), respectively, with a Minolta CR-400 Chroma meter (Minolta Camera Co., Ltd., Osaka, Japan). The sliced chops were then kept frozen. The 2.54-cm thick chops were taken out from frozen storage $\left(-41^{\circ} \mathrm{C}\right) 24 \mathrm{~h}$ prior to analysis and allowed to thaw completely. Secondary muscles and excess subcutaneous muscles were trimmed. Then the slice shear force (SSF) was determined as described by Wilson et al. (2017). Intramuscular fat percent (IMF) was based on the extractable lipid content of each chop as described by Wilson et al. (2017).

Statistical analysis. The data were analyzed using the single step genomic BLUP (Legarra et al., 2009) using BLUPF90 (Misztal et al., 2015). Univariate analyses were conducted to obtain a first estimate of heritabilities and variance components.
Heritabilities and genetic correlations between male and female for different traits were also estimated in similar fashion. Single trait models were fitted as

$$
\mathrm{y}_{\mathrm{ijklm}}=\mu+\mathrm{D}_{\mathrm{i}}+\mathrm{C}_{\mathrm{j}}+\mathrm{G}_{\mathrm{k}}+\mathrm{a}_{\mathrm{l}}+\mathbf{p}_{\mathrm{m}(\mathrm{j})}+\mathrm{e}_{\mathrm{ijklm}},
$$

where $y_{i j k l m}$ is the trait measured, $\mu$ is the intercept, $\mathrm{D}_{\mathrm{i}}$ is the $i$ th effect of the dam line (2 levels), $\mathrm{C}_{\mathrm{j}}$ is the $j$ th effect of contemporary group (6 levels); $\mathrm{G}_{\mathrm{k}}$ is the $k$ th effect of the gender ( 2 levels), $a_{1}$ is the random additive genetic effect, $\mathrm{p}_{\mathrm{m}(\mathrm{j})}$ is the random effect of pen nested in contemporary group, and $\mathrm{e}_{\mathrm{ijklm}}$ is the random residual error. Covariance matrices of the pen and residuals were equal to $\boldsymbol{I} \sigma_{p}^{2}$ and $\boldsymbol{I} \sigma_{e}^{2}$, where $\boldsymbol{I}$ is an identity matrix. Initially, the model also included the random litter effect and random permanent environmental effect. The variance absorbed by litter and permanent environmental effect was close to zero. So, these 2 effects were removed from all analyses for all traits. The random effect of animal was given by covariance matrix of $\boldsymbol{H} \sigma_{l}^{2}$ in which $\mathbf{H}$ was blended genomic and pedigree relationship matrix (Forni et al., 2011). $\mathbf{H}^{-1}$ was calculated as follows:

$$
\mathbf{H}^{-1}=\mathbf{A}^{-1}+\left[\begin{array}{cc}
0 & 0 \\
0 & \mathbf{G}^{-1}-\mathbf{A}_{22}^{-1}
\end{array}\right],
$$

where $\mathbf{G}^{-1}$ is the inverse of the genomic relationship matrix, $\mathbf{A}^{-1}$ is the inverse numerator relationship matrix (A), and $\boldsymbol{A}_{22}^{-1}$ is the inverse of pedigree-based relationship matrix for genotyped animals (Forni et al. , 2011). All the individuals with detailed phenotypes $(n=1,254)$ had genomic information available. G was created according to VanRaden (2008),

$$
\mathrm{G}=\frac{(\mathrm{M}-\mathrm{P})(\mathrm{M}-\mathrm{P})^{\prime}}{2 \sum_{\mathrm{j}=1}^{\mathrm{m}} \mathrm{p}_{\mathrm{j}}\left(1-\mathrm{p}_{\mathrm{j}}\right)},
$$

where $\mathbf{M}$ is a matrix of marker alleles with $m$ columns ( $m=$ total number of markers) and $n$ rows ( $n=$ total number of genotyped individuals), and $\mathbf{P}$ is a matrix containing the frequency of the second allele $\left(p_{j}\right)$, expressed as $2 p_{j}$. $\mathbf{M}_{\mathbf{i j}}$ was -1 if the genotype of individual $i$ for SNP $j$ was homozygous for the first allele, 0 if heterozygous and 1 if the genotype was homozygous for the second allele. Bivariate analyses were conducted to estimate the genetic and phenotypic correlations. Multi trait models were of form,

$\left[\begin{array}{l}y_{1} \\ y_{2}\end{array}\right]=\left[\begin{array}{ll}X_{1} & 0 \\ 0 & X_{2}\end{array}\right]\left[\begin{array}{l}b_{1} \\ b_{2}\end{array}\right]+\left[\begin{array}{ll}Z_{1} & 0 \\ 0 & Z_{2}\end{array}\right]\left[\begin{array}{l}a_{1} \\ a_{2}\end{array}\right]+\left[\begin{array}{ll}W_{1} & 0 \\ 0 & W_{2}\end{array}\right]\left[\begin{array}{l}p_{1} \\ p_{2}\end{array}\right]+\left[\begin{array}{l}e_{1} \\ e_{2}\end{array}\right]$, 
where $y_{1}$ and $y_{2}$ are the vector of phenotypic measurements for traits 1 and 2, respectively; $X_{1}$ and $X_{2}$ are the incidence matrices relating the fixed effects to vector $y_{1}$ and $y_{2}$, respectively; $b_{1}$ and $b_{2}$ are the vector of fixed effect for trait 1 and trait 2 , respectively; $Z_{1}$ and $Z_{2}$ are the incidence matrices relating the phenotypic observations to the vector of random animal effects for trait 1 and trait 2, respectively; $a_{1}$ and $a_{2}$ are the vector of random animal effect for trait 1 and trait 2, respectively; $W_{1}$ and $W_{2}$ are the incidence matrices relating the phenotypic observations to the vector of random pen effects for trait 1 and trait 2, respectively; $p_{1}$ and $p_{2}$ are the vector of random pen effect for trait 1 and trait 2, respectively; and $e_{1}$ and $e_{2}$ are the vectors of random residuals for trait 1 and trait 2, respectively. The fixed effects and random effects were the same as the ones fitted in the univariate analyses.

The additive variance was assumed to be $\operatorname{Var}\left[\begin{array}{l}a_{1} \\ a_{2}\end{array}\right]=\mathbf{C} \otimes \mathbf{H}$, where $\mathbf{C}=\left[\begin{array}{cc}\sigma_{g 1}^{2} & \sigma_{g 21} \\ \sigma_{g 12} & \sigma_{g 2}^{2}\end{array}\right]$. The components of covariance matrix $\mathbf{C}$ were defined as follows: $\sigma_{g 1}^{2}$ is the additive genetic variance for trait 1 , $\sigma_{g 2}^{2}$ is the additive genetic variance for trait 2 , and $\sigma_{g 12}=\sigma_{g 12}$ is the additive genetic covariance between trait 1 and trait 2 . The pen variance was assumed to be $\operatorname{Var}\left[\begin{array}{l}p_{1} \\ p_{2}\end{array}\right]=\mathbf{P} \otimes \mathbf{I}$, where $\mathbf{P}=\left[\begin{array}{ll}\sigma_{p 1}^{2} 0 \\ 0 & \sigma_{p 2}^{2}\end{array}\right]$ and $\mathbf{I}$ is the identity matrix. The components of $\mathbf{P}$ matrix were defined as follows: $\sigma_{p 1}^{2}$ is the pen variance for trait 1 and $\sigma_{p 2}^{2}$ is the pen variance for trait 2. From a preliminary analysis (data not shown), it was found that variance for the pen effect on $\mathrm{PH}$, $\mathrm{HCW}$, and CADG was zero. Therefore, the variance of pen effect for those traits was fixed to zero for the subsequent analyses. The residual variance was given by $\operatorname{Var}\left[\begin{array}{l}e_{1} \\ e_{2}\end{array}\right]=\mathbf{R} \otimes \mathbf{I}$, where
$\mathbf{R}=\left[\begin{array}{cccc}\sigma_{M 1}^{2} & 0 & \sigma_{M 12} & 0 \\ 0 & \sigma_{F 1}^{2} & 0 & \sigma_{F 12} \\ \sigma_{M 21} & 0 & \sigma_{M 2}^{2} & 0 \\ 0 & \sigma_{F 21} & 0 & \sigma_{F 2}^{2}\end{array}\right]$ and $\mathbf{I}$ is the identity matrix. The components of $\mathbf{R}$ were defined as follows: $\sigma_{M 1}^{2}$ is the residual variance associated with male for trait $1, \sigma_{F 1}^{2}$ is the residual variance associated with female for trait $1, \sigma_{M 2}^{2}$ is the residual variance associated with male for trait $2, \sigma_{F 2}^{2}$ is the residual variance associated with female with trait 2 , $\sigma_{M 12}=\sigma_{M 21}$ is the residual covariance associated with male for trait 1 and trait 2 , and $\sigma_{F 12}=\sigma_{F 21}$ is the residual covariance associated with female for trait 1 and trait 2.

\section{Smithfield Premium Genetics}

Animals. Data were collected from over 35,000 Duroc-sired terminal crossbred swine raised by Smithfield Premium Genetics (Roseville, NC). Pedigree for all sires $(n=3,446)$ were traced back for 10 generations and 1,156 sires were genotyped. Pedigree information was not available for dams. Genotypes were obtained for 29 animals from GGP PorcineSNP60 BeadChip (GeneSeek, Neogen Corp.), 793 animals from PorcineSNP80 BeadChip (GeneSeek, Neogen Corp.), 2 animals from Genomic Profiler 10k BeadChip (GeneSeek, Neogen Corp.), 52 animals from Infinium PorcineSNP60v1 BeadChip (Illumina, Inc., San Diego, CA), and 280 animals from Infinium PorcineSNP60 v2 BeadChip (Illumina, Inc., San Diego, CA). All animals were imputed to have a set of 45,747 SNP on GGP Porcine Beadchip (GeneSeek, Neogen Corp.) using FImpute 2.2 (Sargolzaei et al., 2014). Quality control procedures for SPG were the same as in TML. The number of SNPs was 35,186 after quality control. Genotypes for crossbred pigs were not available in this population. The phenotypic data were collected from 2008 to 2017 from 7 different farms. Data were collected for different traits from different contemporary groups ranging from 27 to 71 depending on traits. Contemporary groups were created by concatenation of harvest year, pig farm, and sex of pigs. All the males were castrated.

Data collection. Pigs were immobilized via carbon dioxide stunning and slaughtered by exsanguination. Fat depth and LD were measured by Fat-O-Meater probe (Carometec A/S, Denmark) between the 9th rib and the last rib in the carcass before measuring the HCW. Hot carcass weight was recorded as the same as TML. Then the carcass was transferred to the blast, which helped to cool down the carcass quickly and contained the fans blowing air towards the carcass at $-26{ }^{\circ} \mathrm{C}$; however, the room temperature was maintained at $-14{ }^{\circ} \mathrm{C}$. Following the blast, carcasses were placed at the cooler $\left(-1{ }^{\circ} \mathrm{C}\right.$ to $\left.2{ }^{\circ} \mathrm{C}\right)$ for $24 \mathrm{~h}$. After $24 \mathrm{~h}$ postmortem, the temperature of carcass was around $2{ }^{\circ} \mathrm{C}$. Then center cut boneless loin and belly weights (LOIN2 and BEL2, respectively) were recorded. The LOIN2 was measured in such a way that all rib end, bones, and belly strap with less than one square inch were removed. Furthermore, fat was also trimmed from it so as not to exceed oneeighth inch. Skin-less and skin-on belly weight were recorded from 2 different farms. The genetic correlation [high posterior density interval] of skin-less 
and skin-on belly weight was 0.96 [0.91, 0.99]. So, it was treated as single trait as BEL2. All the further traits were measured on LOIN2 at the same time. The 6 subjective color $(\mathbf{S C O L})$ categories $(1=$ pale pinkish gray to white, $2=$ grayish pink, $3=$ reddish pink, $4=$ dark reddish pink, $5=$ purplish red, and $6=$ dark purplish red) were classified using the guidelines declared by the National Pork Producers Council (1999). The subjective marbling (SMARB) scores were measured on the basis of 10 marbling categories $(1,2,3,4,5,6,7,8,9$, and 10), which were classified using the guidelines as described by the National Pork Producers Council (1999) where 10 represented abundant fat and 1 represented devoid of fat. Subjective firmness score (SFIRM) was measured using the scale from 1 to 3 , where 1 was the softest and 3 was the firmest. Ultimate $\mathrm{pH}$ (PH) was measured on boneless loin by portable pH-meter 1140 (Mettler-Toledo LCC, Columbus, OH). Loin yield (LOINY2), belly yield (BELY2), and carcass average daily gain (CADG) were calculated with the same procedure as for TML.

Statistical analysis. Single and multitrait analyses for estimation of heritability, variance components, and genetic and phenotypic correlations were again conducted with BLUPF90. Fixed effects included 6 levels of parity of dam, 2 levels of gender, and contemporary group ranging from 28 to 71 levels depending on the trait. Fixed effects and random effects were the same for both single and multitrait models. Single trait model had form

$$
\mathrm{y}_{\mathrm{ijklm}}=\mu+\mathrm{P}_{\mathrm{i}}+\mathrm{G}_{\mathrm{j}}+\mathrm{C}_{\mathrm{k}}+\mathrm{a}_{\mathrm{l}}+\mathrm{h}_{\mathrm{m}}+\mathrm{e}_{\mathrm{ijklm}},
$$

where $y_{i j k l m}$ is the trait measured, $\mu$ is the intercept, $\mathrm{P}_{\mathrm{i}}$ is the effect of $i$ th parity, $\mathrm{G}_{\mathrm{j}}$ is the effect of $j$ th gender, $\mathrm{C}_{\mathrm{k}}$ is the effect of $k$ th contemporary group, $\mathrm{a}_{\mathrm{l}}$ is the random animal effect, $\mathrm{h}_{\mathrm{m}}$ is the random effect of harvest group, and $\mathrm{e}_{\mathrm{ijklm}}$ is the residual error. Covariance matrices of the harvest batch and residuals were equal to $\boldsymbol{I} \sigma_{h}^{2}$ and $\boldsymbol{I} \sigma_{e}^{2}$, where $\boldsymbol{I}$ is an identity matrix. The random effect of animal was given by covariance matrix of $\boldsymbol{H} \sigma_{l}^{2}$ in which $\mathbf{H}$ was estimated following the same process as TML. Initially, the model also included the random litter effect and random permanent environmental effect in addition to other random effects. The variance absorbed by litter and permanent environmental effect was close to zero. So, these 2 effects were removed from all analyses for all traits. Multitrait model was similar to that of TML except random effect of pen was replaced by random effect of harvest group. Harvest group was defined as a group of pigs harvested together at the same date.

The harvest group variance was assumed to be $\operatorname{Var}\left[\begin{array}{l}h_{1} \\ h_{2}\end{array}\right]=\mathbf{P} \otimes \mathbf{I}$, where $\mathbf{P}=\left[\begin{array}{ll}\sigma_{h 1}^{2} 0 \\ 0 & \sigma_{h 2}^{2}\end{array}\right]$ and $\mathbf{I}$ is the identity matrix. The components of $\mathbf{P}$ matrix were defined as $\sigma_{h 1}^{2}$ is the harvest group variance for trait1 and $\sigma_{h 2}^{2}$ is the harvest group variance for trait 2. From the preliminary analyses, it was found that harvest group variance for PH, LD, SLAGE, HCW, and CADG was zero, so the variance for this effect was fixed to zero in every analysis for those traits. The zero variance of harvest group was due to the same harvest date.

Heritabilities and correlations. For both populations, a Gibbs Sampling algorithm was used with 120,000 iterations, with the first 20,000 samples discarded as burn-in. Samples were saved every 20 iterations for posterior calculations. The posterior mean was used as the estimate of (co) variance components. Lower and upper bounds of $95 \%$ highest posterior density interval for variance components, heritabilities, and genetic and phenotypic correlations were estimated from the stored samples. Heritabilities for TML were calculated as $h^{2}=\frac{\sigma_{a}^{2}}{\sigma_{a}^{2}+\sigma_{p}^{2}+\sigma_{e}^{2}}$ and heritability for SPG was calculated as $h^{2}=\frac{\sigma_{a}^{2}}{\sigma_{a}^{2}+\sigma_{h}^{2}+\sigma_{e}^{2}}$, where $\sigma_{e}^{2}$ is the residual variance and calculated as $\sigma_{e}^{2}=\frac{n_{m} \sigma_{m}^{2}+n_{f} \sigma_{f}^{2}}{n_{t}}$ . Here $n_{m}$ is the number of males in population, $n_{f}$ is the number of females in population, $\sigma_{m}^{2}$ is the residual variance for male, $\sigma_{f}^{2}$ is the residual variance for female, and $n_{t}$ is the total number of populations. Genetic correlations were calculated as $r_{g}=\frac{\sigma_{g 12}}{\sqrt{\sigma_{g 1}^{2} * \sigma_{g 2}^{2}}}$.

\section{RESULTS AND DISCUSSION}

\section{Data Summary}

Means, standard deviations, number of measurements per trait, and minimum and maximum values for each meat quality and carcass composition traits of TML and SPG are given in Tables 1 and 2, respectively. There were 14 carcass traits, 3 growth traits and 9 meat quality traits for TML, and 5 carcass traits, 4 growth traits, and 4 meat quality traits for SPG. The relevant fixed and random effects fitted in the mixed model analysis for carcass, growth, and meat quality traits of TML 
Table 1. Descriptive statistics for growth, meat quality, primal weight, and primal yield traits:number of animals per trait $(n)$, mean, $\mathrm{SD}$, minimum (Min), and maximum (Max) values of TML

\begin{tabular}{|c|c|c|c|c|c|c|}
\hline Traits & Acronym & $n$ & Mean & SD & Min & Max \\
\hline \multicolumn{7}{|l|}{ Growth traits } \\
\hline Loin depth, mm & LD & 4,894 & 66.78 & 6.91 & 91.44 & 226.06 \\
\hline Back fat depth, mm & FD & 4,893 & 22.62 & 4.88 & 25.4 & 129.54 \\
\hline Carcass average daily gain, $\mathrm{g} / \mathrm{d}$ & CADG & 5,124 & 560.00 & 70.00 & 32.00 & 950.00 \\
\hline \multicolumn{7}{|l|}{ Meat quality } \\
\hline Intra muscular fat, $\%$ & IMF & 1,227 & 2.71 & 0.93 & 0.44 & 7.23 \\
\hline Minolta $a^{*}$ & MINA & 1,241 & 3.79 & 1.10 & 0.68 & 7.89 \\
\hline Minolta $b^{*}$ & MINB & 1,236 & -0.15 & 0.91 & -2.45 & 3.43 \\
\hline Minolta $L^{*}$ & MINL & 1,241 & 45.30 & 3.10 & 35.98 & 56.58 \\
\hline Ultimate $\mathrm{pH}$ & $\mathrm{PH}$ & 1,171 & 5.64 & 0.18 & 5.03 & 6.91 \\
\hline Subjective color & SCOL & 1,237 & 2.72 & 0.47 & 2.0 & 4.00 \\
\hline Subjective marbling & SMARB & 1,237 & 3.10 & 0.83 & 1.00 & 6.00 \\
\hline Subjective firmness & SFIRM & 1,237 & 3.04 & 0.99 & 1.00 & 5.00 \\
\hline Slice shear force, $\mathrm{kg}$ & SSF & 1,227 & 15.90 & 3.65 & 9.06 & 39.93 \\
\hline \multicolumn{7}{|l|}{ Primal weight trait } \\
\hline Ham weight, $\mathrm{kg}$ & HAM & 1,254 & 25.19 & 2.34 & 18.09 & 32.07 \\
\hline Loin weight, $\mathrm{kg}$ & LOIN1 & 1,254 & 23.04 & 2.16 & 16.92 & 30.98 \\
\hline Belly weight, $\mathrm{kg}$ & BEL1 & 1,254 & 18.28 & 2.78 & 10.70 & 26.71 \\
\hline Sparerib weight, $\mathrm{kg}$ & SRIB & 1,254 & 5.00 & 0.67 & 3.08 & 7.17 \\
\hline Picnic weight, $\mathrm{kg}$ & $\mathrm{PICN}$ & 1,254 & 7.03 & 1.18 & 7.85 & 15.20 \\
\hline Butt weight, kg & BUTT & 1,254 & 9.51 & 1.09 & 6.26 & 12.93 \\
\hline Hot carcass weight, $\mathrm{kg}$ & $\mathrm{HCW}$ & 5,124 & 103.11 & 11.51 & 60.33 & 186.43 \\
\hline \multicolumn{7}{|l|}{ Primal yield trait } \\
\hline Ham yield, $\%$ & HAMY & 1,242 & 24.37 & 1.01 & 19.42 & 27.61 \\
\hline Loin yield, \% & LOINY1 & 1,242 & 22.34 & 1.08 & 18.79 & 26.74 \\
\hline Belly yield, \% & BELY1 & 1,242 & 17.59 & 1.41 & 12.61 & 22.40 \\
\hline Sparerib yield, $\%$ & SRIBY & 1,242 & 4.83 & 0.36 & 3.70 & 6.16 \\
\hline Picnic yield, $\%$ & PICNY & 1,242 & 11.20 & 0.73 & 8.45 & 15.27 \\
\hline Butt yield, \% & BUTTY & 1,242 & 9.19 & 0.68 & 6.46 & 12.51 \\
\hline Primal yield, $\%$ & PRIMY & 1,242 & 89.48 & 1.22 & 82.96 & 96.02 \\
\hline
\end{tabular}

Table 2. Descriptive statistics for growth, meat quality, primal weight, and primal yield traits: number of animals per trait (n), mean, SD, minimum (Min), and maximum (Max) values of SPG

\begin{tabular}{|c|c|c|c|c|c|c|}
\hline Traits & Acronym & $n$ & Mean & $\mathrm{SD}$ & Min & Max \\
\hline \multicolumn{7}{|l|}{ Growth traits } \\
\hline Fat depth, mm & FD & 42,783 & 20.52 & 4.74 & 2.00 & 36.00 \\
\hline Loin depth, mm & LD & 40,951 & 58.10 & 7.07 & 45.00 & 75.00 \\
\hline Slaughter age, $\mathrm{d}$ & SLAGE & 320,545 & 186.00 & 13.69 & 152.00 & 225.00 \\
\hline Carcass average daily gain, $\mathrm{g} / \mathrm{d}$ & CADG & 320,545 & 520.00 & 60.00 & 250.00 & 810.00 \\
\hline \multicolumn{7}{|l|}{ Meat quality traits } \\
\hline Subjective color & SCOL & 51,168 & 3.24 & 0.62 & 1.00 & 6.00 \\
\hline Subjective firmness & SFIRM & 49,323 & 2.19 & 0.69 & 1.00 & 3.00 \\
\hline Subjective marbling & SMARB & 51,246 & 2.51 & 1.02 & 1.00 & 10.00 \\
\hline Ultimate $\mathrm{pH}$ & PH & 24,713 & 5.69 & 0.16 & 4.50 & 6.90 \\
\hline \multicolumn{7}{|l|}{ Primal weight traits } \\
\hline Belly weight, $\mathrm{kg}$ & BEL2 & 37,539 & 7.16 & 0.57 & 4.79 & 8.40 \\
\hline Loin weight, $\mathrm{kg}$ & LOIN2 & 46,892 & 3.17 & 0.44 & 1.96 & 4.27 \\
\hline Hot carcass weight, $\mathrm{kg}$ & $\mathrm{HCW}$ & 320,468 & 96.27 & 10.15 & 53.64 & 135.91 \\
\hline \multicolumn{7}{|l|}{ Primal yield traits } \\
\hline Belly yield, \% & BELY2 & 37,539 & 7.44 & 0.76 & 4.17 & 12.8 \\
\hline Loin yield, \% & LOINY2 & 46,892 & 3.29 & 0.44 & 2.3 & 4.20 \\
\hline
\end{tabular}


and SPG are given in Supplementary Tables S1 and $\mathrm{S} 2$, respectively.

\section{Genetic Material, Model, and Experimental Setup for $T M L$}

This study was conducted on 3-way-crossbred pigs obtained from 1 sire line (Duroc) and F1 sows (Yorkshire $\times$ Landrace and Landrace $\times$ Yorkshire). Genomic and phenotypic information was collected from terminal cross, but genomic information of F1 sows was not available. Different authors (Christensen et al., 2015; Sevillano et al., 2017) employed models with partial genetic effect tracing the breed-of-origin of alleles of crossbred individuals when predicting crossbreds. This model could not be used in this study because of the lack of genomic information for $F_{1}$ sows and for three purebred populations, which is one limitation of this study.

\section{Heritability Estimates}

Heritabilities and variance components estimates of growth, meat quality, and carcass traits (primal weights and primal yields) are presented in Table 3 for TML, and Table 4 for SPG. All the remaining estimates along with their respective high posterior density intervals are provided in Supplementary Tables S3 and S4 for TML and SPG, respectively.

For TML, heritability estimates [high posterior density interval] for growth traits were moderate except for LD, which was 0.15 [0.09, 0.21]. Moderate heritabilities of growth traits were also reported in previous studies (Lo et al., 1992; Clutter, 2011; Miar et al., 2014a). Miar et al. (2014b), Jiao et al. (2014) and Hicks et al. (1998) reported a moderate heritability of ADG, which agreed with present study, but less than that of Cabling et al. (2015) who reported an estimate of 0.67 . This higher estimate might be due to differences in the measurement of ADG than that of our study. The present study measured the carcass average daily gain; however, Cabling et al. (2015) measured the average daily gain of live weight. The heritability of FD in this study agreed with previous studies (Clutter and Brasscamp, 1998; Sonenson et al., 1998; van Wijk et al., 2005; Ciobanu et al., 2011; Miar et al., 2014b). The heritability of LD in this study agreed with Van Wijk et al. (2005) and de Campos et al. (2015). However, the heritability of LD was less than some of the previous studies (Ducos, 1993; Magniel et al., 2010; Miar et al., 2014a).
Table 3. Heritabilities $\left(\mathrm{h}^{2}\right)$, genetic variance $\left(\sigma_{\mathrm{a}}^{2}\right)$, pen variance $\left(\sigma_{\mathrm{p}}^{2}\right)$, residual variance of female $\left(\sigma_{\mathrm{f}}^{2}\right)$, residual variance of male $\left(\sigma_{\mathrm{m}}^{2}\right)$ of growth, meat quality, primal weight, and primal yield traits of TML

\begin{tabular}{|c|c|c|c|c|c|}
\hline Traits $^{1}$ & $\mathrm{~h}^{2}$ & $\sigma_{a}^{2}$ & $\sigma_{p}^{2}$ & $\sigma_{\mathrm{f}}^{2}$ & $\sigma_{m}^{2}$ \\
\hline \multicolumn{6}{|c|}{ Growth traits } \\
\hline LD & 0.15 & 7.33 & 1.64 & 37.60 & 39.88 \\
\hline FD & 0.47 & 10.67 & 0.65 & 9.48 & 13.01 \\
\hline CADG & 0.44 & 2.43 & 0.03 & 2.65 & 3.06 \\
\hline \multicolumn{6}{|c|}{ Meat quality } \\
\hline IMF & 0.52 & 0.004 & 0.0004 & 0.002 & 0.004 \\
\hline MINA & 0.19 & 0.22 & 0.16 & 0.73 & 0.80 \\
\hline MINB & 0.08 & 0.0006 & 0.001 & 0.004 & 0.005 \\
\hline MINL & 0.20 & 1.96 & 1.43 & 6.02 & 6.44 \\
\hline PH & 0.08 & 0.003 & 0.01 & 0.02 & 0.02 \\
\hline SCOL & 0.26 & 0.06 & 0.01 & 0.16 & 0.15 \\
\hline SMARB & 0.27 & 0.18 & 0.09 & 0.44 & 0.40 \\
\hline SFIRM & 0.12 & 0.12 & 0.05 & 0.89 & 0.72 \\
\hline SSF & 0.21 & 0.37 & 0.08 & 1.48 & 1.10 \\
\hline \multicolumn{6}{|c|}{ Primal weight trait } \\
\hline HAM & 0.14 & 1.71 & 0.05 & 10.70 & 10.25 \\
\hline LOIN1 & 0.18 & 1.80 & 0.05 & 8.81 & 8.11 \\
\hline BEL1 & 0.22 & 3.78 & 0.06 & 14.41 & 11.85 \\
\hline SRIB & 0.30 & 0.31 & 0.005 & 0.72 & 0.71 \\
\hline PICN & 0.12 & 0.35 & 0.02 & 2.85 & 2.63 \\
\hline BUTT & 0.20 & 0.52 & 0.02 & 2.17 & 2.06 \\
\hline $\mathrm{HCW}$ & 0.39 & 42.9 & 0.09 & 65.49 & 68.86 \\
\hline \multicolumn{6}{|c|}{ Primal yield trait } \\
\hline HAMY & 0.45 & 4.38 & 0.44 & 4.60 & 4.78 \\
\hline LOINY1 & 0.33 & 3.73 & 0.56 & 7.22 & 7.13 \\
\hline BELY1 & 0.33 & 6.22 & 0.30 & 13.44 & 11.33 \\
\hline SRIBY & 0.35 & 7.85 & 1.05 & 13.36 & 13.63 \\
\hline PICNY & 0.32 & 1.58 & 0.33 & 3.29 & 2.84 \\
\hline BUTTY & 0.17 & 0.74 & 0.23 & 3.68 & 3.41 \\
\hline PRIMY & 0.21 & 2.98 & 0.34 & 9.37 & 12.35 \\
\hline
\end{tabular}

${ }^{1} \mathrm{LD}=$ Loin depth $; \mathrm{FD}=$ Fat depth $;$ CADG $=$ Carcass average daily gain; $\mathrm{IMF}=$ Intramuscular fat percent, MINA = Minolta $\mathrm{a}^{*}$, MINB $=$ Minolta $b^{*}$, MINL $=$ Minolta $L^{*}, \mathrm{PH}=$ Ultimate $p H$; SCOL = Subjective color score; SMARB $=$ Subjective marbling score; SFIRM = Subjective firmness score; SSF = Slice shear force, HAM = Ham weight; LOIN1 = Loin weight; BEL1 = Belly weight; SRIB $=$ Spare rib weight, PICN = Picnic weight BUTT $=$ Butt weight; $\mathrm{HCW}=$ Hot carcass weight; HAMY $=$ Ham yield; LOINY1 = Loin yield; BELY1 = Belly yield; SRIBY $=$ Spare rib yield; PICNY $=$ Picnic yield; BUTTY = Butt yield; PRIMY = Primal yield.

The heritability estimates of meat quality traits for TML ranged from $0.08[0.03,0.1]$ for $\mathrm{PH}$ to $0.27[0.22,0.32]$ for SMARB except for IMF, which had the heritability estimate of $0.52[0.40,0.62]$. This agreed with previous studies (Lo et al., 1992; de vries et al.,1994; Sellier, 1998; Lee et al., 2015). Newcom et al. (2005) mentioned that IMF was the important physicochemical trait of meat quality, which affected the sensory characteristics of pork and was associated with other traits like marbling 
Table 4. Heritabilities $\left(\mathrm{h}^{2}\right)$, genetic variance $\left(\sigma_{\mathrm{a}}^{2}\right)$, variance of harvest batch $\left(\sigma_{\mathrm{h}}^{2}\right)$, residual variance of female $\left(\sigma_{\mathrm{f}}^{2}\right)$, residual variance of male $\left(\sigma_{\mathrm{m}}^{2}\right)$ of growth, meat quality, primal weight, and primal yield traits of SPG

\begin{tabular}{lcccrr}
\hline \hline Traits $^{1}$ & $\mathrm{~h}^{2}$ & $\sigma^{2}{ }_{\mathrm{a}}$ & $\sigma_{\mathrm{h}}^{2}$ & $\sigma_{\mathrm{f}}^{2}$ & $\sigma_{\mathrm{m}}^{2}$ \\
\hline Growth traits & & & & & \\
FD & 0.45 & 7.26 & 0.92 & 6.64 & 9.64 \\
LD & 0.20 & 4.68 & $\mathrm{NC}^{2}$ & 18.40 & 20.13 \\
SLAGE & 0.59 & 50.07 & $\mathrm{NC}$ & 65.28 & 69.55 \\
CADG & 0.42 & 0.10 & $\mathrm{NC}$ & 0.10 & 0.20 \\
Meat quality traits & & & & \\
SCOL & 0.24 & 0.07 & 0.05 & 0.17 & 0.29 \\
SFIRM & 0.24 & 0.11 & 0.02 & 0.31 & 0.31 \\
SMARB & 0.33 & 0.28 & 0.07 & 0.41 & 0.56 \\
PH & 0.24 & 0.004 & 0.01 & 0.01 & 0.02 \\
Primal weight traits & & & & \\
BEL2 & 0.22 & 0.06 & 0.06 & 0.16 & 0.17 \\
LOIN2 & 0.39 & 0.03 & 0.01 & 0.03 & 0.03 \\
HCW & 0.30 & 21.90 & $\mathrm{NC}$ & 50.88 & 52.67 \\
Primal yield traits & & & & \\
BELY2 & 0.19 & 0.09 & 0.06 & 0.22 & 0.25 \\
LOINY2 & 0.28 & 0.04 & 0.02 & 0.05 & 0.07 \\
\hline
\end{tabular}

${ }^{1} \mathrm{FD}=$ Fat depth LD = Loin depth; SLAGE = Slaughter age; $\mathrm{CADG}=$ Carcass average daily gain SCOL $=$ Subjective color score; SFIRM = Subjective firmness score; SMARB = Subjective marbling score; $\mathrm{PH}=$ Ultimate $\mathrm{pH}$; BEL2 = Belly weight; LOIN2 = Loin weight; HCW $=$ Hot carcass weight; BELY2 = Belly yield; LOINY2 $=$ Loin yield

and color. Marbling score is related to IMF. The heritability of SMARB was moderate. This was in concordance with the range $(0.14-0.31)$ of previous studies (Lo et al., 1992; Sonenson et al., 1998; van Wijk et al., 2005; Miar et al., 2014a).

Heritabilities of instrumental color ranged from 0.08 [0.03, 0.16] for MINB to 0.20 [0.14, 0.29] for MINL. These values were in range as reported by van Wijk et al. (2005) and Lee et al. (2015). The SCOL was moderately heritable, which was in the range as reported by previous studies (Cameron, 1990, Hovenier et al., 1992; Lo et al., 1992; Hermesch et al., 2000a). The heritability of PH in this study was low. The heritability of $\mathrm{PH}$ was in the range of 0.07 to 0.39 as reported by previous authors (Cameron, 1990; Hovenier et al., 1992; De Vries 1994; Suzuki et al., 2005; Van Wijk et al., 2005; Gjerlaug-Enger et al., 2010; Miar et al., 2014a; Lei et al., 2018). The wide range of heritability in these studies could be due to differences in time of recording $\mathrm{pH}$, genetic origin of sampled populations, nutrition of pigs, and differences in preslaughter and postslaughter procedures (Cannon et al. 1995). The SFIRM was lowly heritable which was lower than that of 0.20 and 0.29 as reported by van Wijk et al. (2005) and Lo et al. (1992), respectively. Shear force is related to tenderness. The SSF was moderately heritable which agreed with the previous estimates reported by Lo et al. (1992) and De Vries et al. (1994) but lower than the value (0.39) reported by Miar et al. (2014a) and value $(0.30)$ as reported by the average of several studies by Ciobanu et al. (2011). The effect of heterosis in crossbred population could have affected the variance components and heritability estimates (Miar et al., 2014a) in the present study. The differences among the heritability estimates might also have been due to the difference in composition of population (purebred vs. crossbred), and models (using pedigree information vs. inclusion of genomic information) used in statistical analysis (Lei et al., 2018).

Heritability of HAM in this study was less than that of the range $(0.40$ to 0.63$)$ previously reported estimates (Newcom et al., 2002; van Wijk et al., 2005; Gilbert et al., 2007; Miar et al. 2014a). Loin weight was moderately heritable which was lower than the range of estimates (0.29-0.51) reported by van Wijk et al. (2005), Gilbert et al. (2007) and Newcom et al. (2002). Belly weight was moderately heritable which agreed with Gilbert et al. (2007) but lower than the estimate $(0.51)$ as reported by Newcom et al. (2002). Moderate heritabilities were found for SRIB and BUTT, which agreed with Miar et al. (2014a). Picnic weight was lowly heritable, which was lower than the estimate of 0.44 as reported by Miar et al. (2014a) and 0.21 as reported by Newcom et al. (2002). The difference in previous studies may be due to constant slaughter weight using different carcass measurement techniques and statistical model used for (co)variance estimation. Furthermore, this could be due to the existence of maternal heterosis or heterotic effect itself in the crossbred population and incorporation of genomics in the study. Limited studies on heritability of primal and sub primal cuts weights especially for PICN, BUTT, and SRIB make it difficult for comparison with other studies.

The heritabilities of primal yield traits were higher than that of primal weight traits and ranged from $0.17[0.13,0.25]$ for BUTTY to $0.45[0.36,0.55]$ for HAMY (Table 3). To the best of our knowledge, no literature had been published relative to the heritability of proportion of primal weight traits to compare with previous studies. Further study is warranted. The heritability estimates for primal yield traits were the highest among the study. The high estimate suggested that the selection could be done based on the primal yield traits. 
For SPG, the heritability estimates of growth traits were moderate (Table 4 ) and ranged from $0.42[0.41,0.43]$ for CADG to 0.59 [0.58, 0.62] for SLAGE except LD which has heritability of 0.20 $[0.18,0.22]$. The low heritability of LD and moderate heritability of CADG and FD were in concordance with TML. The heritability estimate of slaughter age agreed with Singh et al. (2001). The literature of heritability of SLAGE is limited in swine for further comparison. The heritability estimates of growth traits were moderate in both populations, which further validate the results and suggested that these traits should respond to selection directly.

Moderate heritability of meat quality traits was found for SPG (Table 4) ranging from 0.24 [0.22, 0.26] for SCOL, SFIRM and PH to 0.33 [0.31, 0.35] for SMARB. These values agreed with TML except for $\mathrm{PH}$. This difference could be due to difference in time of recording of $\mathrm{PH}$, statistical model used for estimation of co(variance) estimation. The heritability of primal yield traits was less than that of primal weight traits in SPG, which was in contrast with results from TML. The difference could be related to constant endpoint of TML, difference in fixed and random effects in statistical model, differences in sample size, differences in measurement techniques of primal weight traits, and different management system.

\section{Correlation Among Traits}

In the discussion of genetic correlations, we will only focus on relevant results and estimates of widely reported combination will not be discussed unless useful in the comparison with the present study.

\section{Correlation Among Meat Quality Traits}

The genetic and phenotypic correlations among meat quality traits of TML and SPG are presented in Figure 1A and B, respectively. All the estimates of genetic and phenotypic correlations for TML and SPG are provided in Supplementary Tables S5 and S6, respectively. Most of the genetic and phenotypic correlations were significant. Marbling and color are important characteristics of meat that could be seen visually by consumers and used for juiciness and tenderness (Lonergan et al., 2007; Wilson et al., 2017). High marbling category and darker meat had high buying probability of pork by consumers (Brewer et al., 1999; Brewer et al., 2001). Marbling and IMF represent the content of fat between muscle. High correlation of 0.74 [0.59, 0.89] was found between IMF and SMARB. Correlations of IMF with minolta color measurements ranged from 0.34 [0.11, 0.57] between IMF and MINA to $0.78[0.55,0.99]$ between IMF and MINB. Higher genetic correlations of IMF with color measurements indicated that higher intramuscular fat is associated with pale meat where pale color was due to high intramuscular fat content (Hermesch et al., 2000b). Subjective marbling score was moderately correlated $(0.45[0.03,0.87])$ to SFIRM. Subjective color was highly negatively correlated with MINB $(-0.93[-1.00,-0.73])$ and MINL $(-0.96[-1.00$, $-0.83]$ ) and moderately positively correlated with MINA $(0.45[0.13,0.74])$. Minolta $a^{*}$ measurement had nonsignificant correlation with MINB and MINL. However, Miar et al. (2014a) reported a significant correlation of Minolta $\mathrm{a}^{*}$ with Minolta
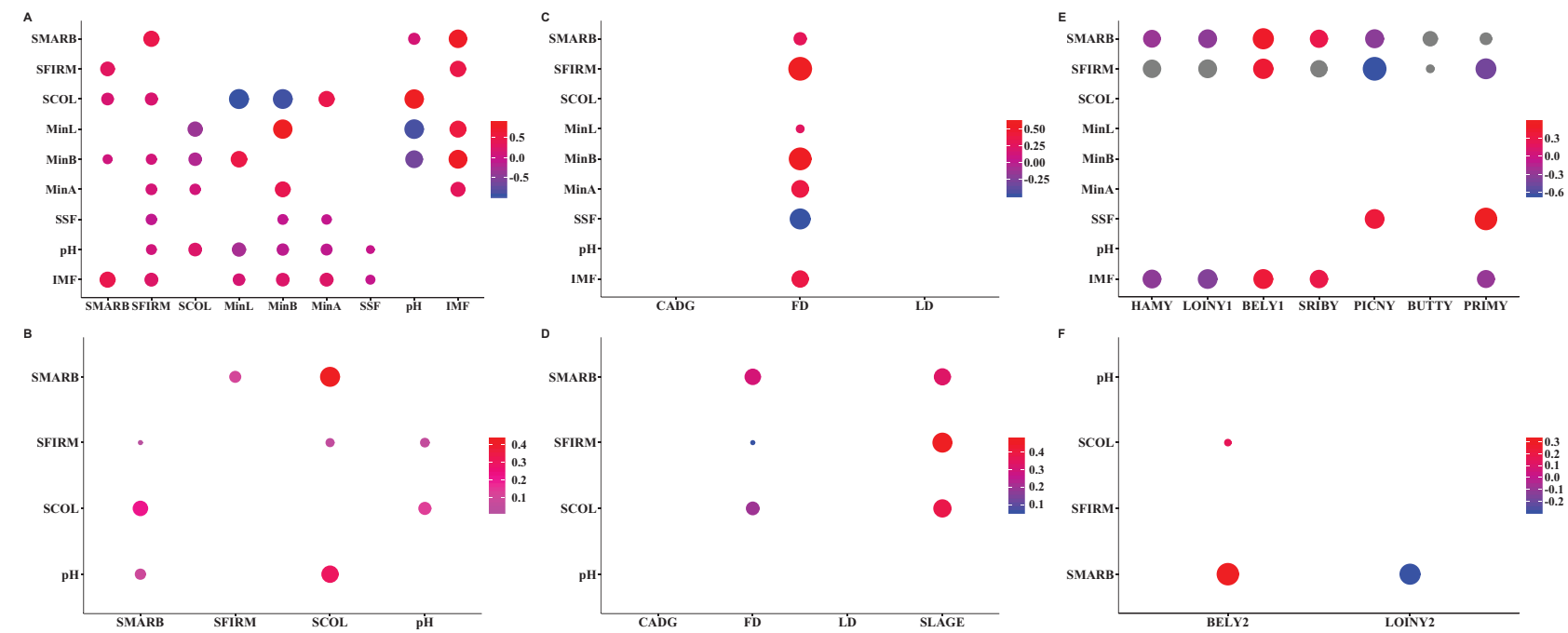

Figure 1. Genetic correlation (upper diagonal) and phenotypic correlation (lower diagonal) among meat quality traits for TML (A) and SPG (B), genetic correlations of meat quality trait with growth traits for TML (C) and SPG (D), genetic correlations of meat quality traits with primal yield traits for TML (E) and SPG (F). Blank spaces represent non-significant correlation. Size of point represents the strength of correlation and color represents the direction of correlation. 
b* (0.46) and Minolta $1 *(-0.40)$. The high positive correlation $(0.86[0.62,0.99])$ of MINB and MINL in the present study agreed with Miar et al. (2014a) and van Wijk et al. (2005). The results indicated that light colored meat was more yellow. The MINA is related to the amount of myoglobin in muscle, which underpin the red color in meat (Mancini and Hunt, 2005). This could explain the positive moderate correlation of MINA and SCOL. $\mathrm{pH}$ had a high positive correlation $(0.87$ [0.56, 1.00]) with SCOL, in agreement with Hovenier et al. (1992). Strong negative correlations were found between $\mathrm{PH}$ with MINB $(-0.64[-1.00,-0.73])$ and MINL $(-0.90[-1.00$, $-0.83])$. This agreed with Hermesch et al. (2000b). Meat color and $\mathrm{pH}$ are highly related. Low $\mathrm{pH}$ is caused by lactic acid buildup, which results in anaerobic breakdown of glucose and glycogen, which loosens the myofibril and scatter more light making the muscle pale (Walters, 1975). Furthermore, low $\mathrm{pH}$ causes the myoglobin to be readily oxidized into metmyoglobin, which causes the discoloration of muscle (Mancini and Hunt, 2005). Shear force is a measure of tenderness and in this study was uncorrelated with other meat quality traits, in agreement with what reported by Miar et al. (2014a).

For SPG, subjective color was weakly correlated to SFIRM $(0.05[0.01,0.09])$ and PH $(0.14$ $[0.02,0.19])$. This was in concordance with the TML results.

\section{Correlations Among Meat Quality With Growth Traits}

The genetic correlations between meat quality traits with growth traits are presented in Figure 1C and D for TML and SPG, respectively. All the estimates of genetic and phenotypic correlations for TML are presented in Supplementary Tables S7 and S8, respectively. All the estimates of genetic and phenotypic correlations for SPG are presented in Supplementary Tables S9 and S10, respectively. There were no significant correlations between meat quality traits and CADG and LD, suggesting that meat quality traits are genetically independent of CADG and LD. This agreed with previous studies (De Vries et al., 1994; Hermesch et al., 2000b; Suzuki et al., 2005; Miar et al. 2014b). However, Van wijk et al. (2005) reported that selection for ADG has a detrimental effect on meat quality. The difference in magnitude of correlations from present study could be due to the use of carcass ADG in the present study rather than live weight measurement in ADG in previous studies. This result suggests that genetic improvement in meat quality had no change in CADG and LD. Fat depth was moderately and positively correlated with meat quality traits except SSF which had moderate negative correlation $(-0.48[-0.70$, $-0.25]$ ) with FD so that selection for lean meat lead to decrease in tenderness. We found no significant correlation of FD with $\mathrm{PH}$ similarly to the results by Miar et al. (2014a). The correlations of FD with MINA (0.38 [0.13, 0.61]), MINB (0.55 [0.22, 0.88]), and MINL $(0.26[0.01,0.51])$ were favorable albeit of moderate magnitude. Consumers preference is towards lean meat with low fat depth. Selection for low FD would therefore results in moderate yellow, moderate light, and moderate red which is the desired color combination. In the present study, unfavorable correlations of FD with SMARB $(0.29[0.06,0.50])$ and IMF $(0.37[0.19,0.55])$ were found. This agreed to previous studies (Cameron, 1990; Hovenier et al., 1992; Hermesch et al., 2000b). Selection for SMARB and IMF would increase FD which might not be desirable from the producers' point of view.

For the SPG and similarly to TML, we did not find significant correlations between meat quality and CADG and LD. The SLAGE trait was unique for SPG. Slaughter age was positively correlated with SCOL $(0.38[0.27,0.43])$, SFIRM (0.47 [0.35, $0.56])$ and SMARB $(0.33[0.22,0.43])$ so that an increase in SLAGE would result in dark red meat, firmer, and with more marbling. The dark color of meat of pigs slaughtered at old age was also found by Virgili et al. (2003).

\section{Correlations Among Meat Quality and Carcass Traits}

Genetic correlations among meat quality and primal yield traits are presented in Figure $1 \mathrm{E}$ and $\mathrm{F}$ for TML and SPG, respectively. All the estimates of genetic and phenotypic correlations for TML and SPG are provided in Supplementary Tables S11S14, respectively. All the estimate for both populations. Moderate negative correlations were found between IMF and HAMY, LOINY1 and PRIMY $(-0.31[-0.50,-0.14],-0.36[-0.57,-0.16]$, and $-0.27[-0.52,-0.01]$, respectively). Similarly, moderate negative correlations were found between SMARB with HAMY $(-0.26[-0.48,-0.03])$ and LOINY1 $(-0.31[-0.57,-0.06])$. Intramuscular fat and SMARB was moderately positively correlated with BELY1 $(0.37[0.15,0.59]$ and $0.45[0.19,0.73]$, respectively) and SRIBY $(0.29[0.09,0.49]$ and 0.28 [0.02, 0.53], respectively). The correlations of SSF with PICNY $(0.36[0.08,0.62])$ and PRIMY (0.55 $[0.22,0.86])$ were moderate and positive. Similar correlations were found between SFIRM and 
BELY1 (0.40 [0.02, 0.77]) while we found moderate to high negative correlations of SFIRM with PRIMY $(-0.43[-0.83,0.02])$ and PICNY $(-0.64$ $[-1.00,-0.29])$. No significant correlations were found between color traits and primal yield traits. The results suggest that genetic improvement for PRIMY and PICNY could result in less tender, firm and intramuscular fat. The results also suggest that selection of higher BELY1 and SRIBY is needed to improve the intramuscular fat which is one of the most important traits for pork quality.

In SPG and contrary to the TML data set, a low positive correlation was found between SCOL and BELY2 $(0.15[0.03,0.20])$. The TML was at constant weight at slaughter, whereas SPG has a variation in slaughter weight. At SPG, when pigs get older they accumulate more fat and their meat were darker in color. The correlations of SMARB with BELY2 and LOINY2 agreed with TML. Subjective marbling score were positively and moderately correlated with BELY2 $(0.32[0.13,0.49])$ in SPG. This is due to fact that white fat is visually distinct in dark red pork compared with pale pork.

\section{Correlation Among Carcass Traits}

All the phenotypic correlations and most of the genetic correlations were significant for primal weight traits (see Supplementary Tables S15 and S16) for both TML and SPG. Moderate to high genetic correlations were found among primal weight traits and ranged from $0.39[0.10,0.65]$ between HAM and BUTT to $0.79[0.66,0.91]$ between BEL1 and SRIB with few being nonsignificant.

The genetic and phenotypic correlations among the primal yield traits for TML are presented in Figure $2 \mathrm{~A}$. All the estimates of genetic and phenotypic correlations for TML are presented in Supplementary Table S17. Ham yield was negatively and moderately correlated with BUTTY $(-0.34[-0.64,-0.03])$, BELY1 ( -0.59 [ $-0.74,-0.43])$, and SRIBY $(-0.45$ $[-0.61,-0.27])$, whereas HAMY was positively and moderately correlated with PICNY $(0.58[0.40,0.75])$ and PRIMY $(0.60[0.43,0.79])$. This suggested that selection of HAMY, PICNY, and PRIMY would decrease BUTTY, BELY1, and SRIBY. Loin yield was highly unfavorably correlated $(-0.70[-0.85$, -0.54]) with BELY1 but positively favorably correlated $(0.39$ [0.13, 0.65]) with PRIMY. Belly yield was moderately and favorably correlated $(0.41[0.17$, $0.64])$ with SRIBY but moderately and unfavorably correlated $(-0.46[-0.71,-0.18])$ with PRIMY. Picnic yield was highly and favorably correlated $(0.68$ [0.47, 0.86]) with PRIMY. This implies that selection of BELY1 would happen at the expense of PRIMY. This could be due to fat deposition in belly muscles. The inverse relationship of SRIBY and BELY1 with LOINY1 and HAMY might be due to disproportionate growth. Lean pigs have more loin and hams, whereas fat pigs have deep belly and spare ribs. The nonsignificant correlations among primal yield traits indicated that different genes could affect the growth and differentiation of muscles in different cut parts. For SPG, no significant correlation was found between BELY2 and LOINY2 which was different from TML. The exact reason for this different relationship could not be tested in our study. This could be due to difference in sample size and statistical models employed. To the best of our knowledge, no literature has been published regarding the correlation of primal yield traits. The cost of measuring primal weight traits might have limited the amount of literature available for more comparison. Thus, future work is needed in this area.

\section{Correlation Among Carcass With Growth Traits}

Primal weight traits have relationships with growth traits similar to previously published studies. All the estimates of genetic and phenotypic correlations of primal weight and yield traits with growth traits for TML and SPG are presented in Supplementary Tables S18-S21, respectively. The genetic correlations among primal yield traits and growth traits for TML are presented in Figure 2B. Primal yield traits were both positively and negatively correlated with average daily gain. Moderate negative correlations were found between CADG with HAMY, LOINY1, PICNY, and PRIMY $(-0.54$ $[-0.73,-0.33],-0.46[-0.67,-0.20],-0.43[-0.66$, $-0.14]$, and $-0.47[-0.60,-0.24]$, respectively), whereas moderate positive correlations were found with BELY1 and SRIBY (0.47 [0.24, 0.70] and 0.48 [0.23, 0.72], respectively), indicating how fast-growing pigs would accumulate muscle and fat more rapidly on belly and ribs compared with other primal cuts. Fat depth was favorably correlated with HAMY, PICNY, LOINY1, and PRIMY (-0.46 $[-0.60,-0.31],-0.57[-0.76,-0.38],-0.64[-0.79$, $-0.48]$, and $-0.52[-0.80,-0.34]$, respectively). However, FD was unfavorably correlated $(0.68$ $[0.54,0.80])$ with BELY1. Moderate negative genetic correlation was found between LD with BELY1 and PRIMY $(-0.42[-0.80,-0.03]$ and $-0.44[-0.78$, $-0.10]$, respectively). For SPG, LOINY2 was unfavorably and moderately correlated to FD $(-0.36$ $[-0.56,-0.16])$. This agreed with TML. Belly yield had moderate correlation $(0.52[0.46,0.58])$ with 

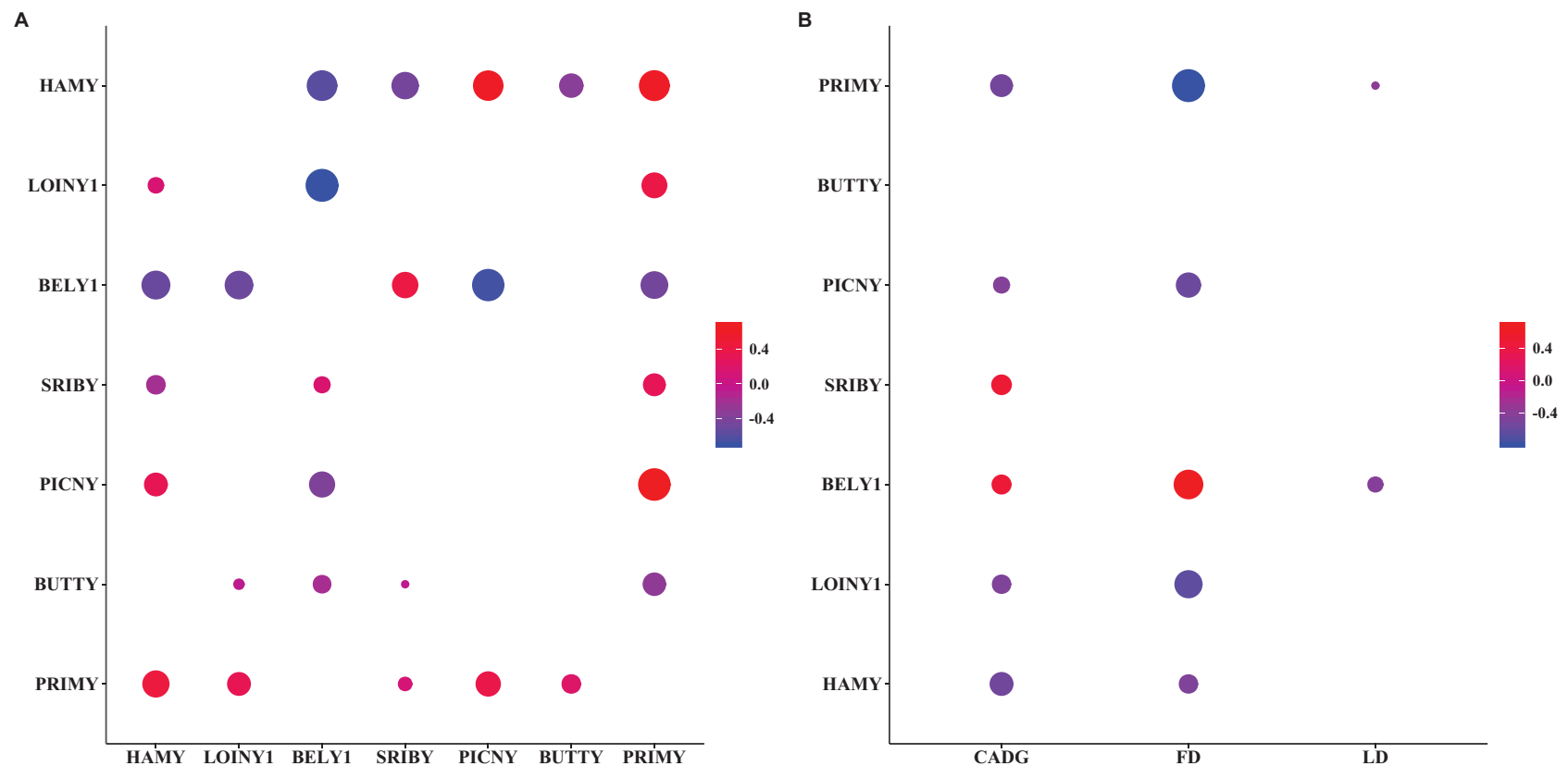

Figure 2. Genetic correlation (upper diagonal) and phenotypic correlation (lower diagonal) among primal yield traits for The Maschhoffs population (A), genetic correlation among primal yield traits and growth traits (B). Blank spaces represent nonsignificant correlation. Size of point represents the strength of correlation and color represents the direction of correlation.

SLAGE, indicating that the pigs that are slaughtered at later age are fatter. Very limited literature estimates are available regarding the correlation of proportion of cut weight with growth traits.

\section{Heritability Estimates and Genetic Correlations Between Male and Female Among Different Traits}

Different papers described differences in heritability between males and females for different traits in human as well as model organism (Wang et al., 2006; Ober et al., 2008). However, literature on heritability estimates and genetic correlations between male and female for different traits in livestock remains limited. Here, we report heritability estimates for castrated male and female, and genetic correlation between castrated male and female for different traits. Results are presented in Table 5 and estimates with confidence interval are provided in Supplementary Table S22. For growth traits, heritability for male and female was fairly similar and genetic correlations were high. Nonsignificant effect of sex on growth rate was presented by Franco et al. (2014) and confirmed the high correlation of ADG in the present study among castrated males and females.

For meat quality traits, there were some discrepancies among heritabilities and genetic correlations. For IMF, the heritability of male was lower than that of the female, possibly due to the fact that deposition of intramuscular fat in male and female occurs at different rates. More fat deposition in female might have caused more variation, which resulted in higher heritability. This result is in concordance to Serrano et al. (2009) and Franco et al. (2014). The difference of IMF between male and female could be explained biologically as testosterone (male hormone) plays an important role in lipolysis and lipoprotein lipase activity inhibition. Lipoprotein lipase helps remove fatty acids from blood to cell and hence the fats are deposited in cells (Power and Schulkin, 2008).

Minolta $\mathrm{a}^{*}$ had higher heritability for females than males. Cui et al. (2014) identified a significant sexually dimorphic locus on chromosome 6 associated with Minolta $\mathrm{a}^{*}$ values, suggesting a different genetic architecture for the trait across sexes. Heritability of LOINY1 for female was higher than that for male, whereas nonsignificant correlation among male and female was found for $\mathrm{PH}$. The exact reason for this is unknown. For MINL, SCOL, SSF, BUTT, SRIBY, and BUTTY, males and females had lower correlation $(<0.9)$. This could be due to the sex-specific effect on these traits. The results from this study indicated that for some traits (MINA, IMF, and LOINY1) it is beneficial to fit model with heterogenous variance.

\section{CONCLUSIONS}

This study utilized pedigree and genomic information for the estimation of genetic parameters in commercial crossbred swine. For meat quality traits, heritabilities ranged from low to moderate whereas moderate to high heritabilities were found for carcass 
Table 5. Genetic correlation $\left(\mathrm{r}_{\mathrm{g}}\right)$ and heritability estimate for male $\left(\mathrm{h}_{\mathrm{m}}^{2}\right)$ and female $\left(\mathrm{h}_{\mathrm{f}}^{2}\right)$ for growth, meat quality, primal weight, and primal yield traits of TML

\begin{tabular}{|c|c|c|c|}
\hline Traits $^{1}$ & $\mathrm{~h}_{\mathrm{m}}^{2}$ & $\mathrm{~h}_{\mathrm{f}}^{2}$ & $r_{p}$ \\
\hline \multicolumn{4}{|c|}{ Growth traits } \\
\hline $\mathrm{LD}$ & 0.11 & 0.15 & $0.97 *$ \\
\hline FD & 0.24 & 0.28 & 0.99 \\
\hline CADG & 0.38 & 0.35 & 0.99 \\
\hline $\mathrm{HCW}$ & 0.33 & 0.33 & 0.99 \\
\hline \multicolumn{4}{|c|}{ Meat quality } \\
\hline IMF & 0.38 & 0.60 & 0.97 \\
\hline MINA & 0.14 & 0.29 & 0.95 \\
\hline MINB & 0.07 & 0.16 & 0.76 \\
\hline MINL & 0.21 & 0.20 & 0.92 \\
\hline $\mathrm{PH}$ & 0.11 & 0.12 & 0.20 \\
\hline SCOL & 0.32 & 0.22 & 0.84 \\
\hline SMARB & 0.23 & 0.30 & 0.94 \\
\hline SFIRM & 0.10 & 0.14 & 0.79 \\
\hline SSF & 0.18 & 0.27 & 0.89 \\
\hline \multicolumn{4}{|c|}{ Primal weight trait } \\
\hline HAM & 0.10 & 0.19 & 0.93 \\
\hline LOIN1 & 0.13 & 0.25 & 0.96 \\
\hline BEL1 & 0.21 & 0.25 & 1.00 \\
\hline SRIB & 0.27 & 0.31 & 0.98 \\
\hline PICN & 0.10 & 0.14 & 0.93 \\
\hline BUTT & 0.19 & 0.20 & 0.89 \\
\hline \multicolumn{4}{|c|}{ Primal yield trait } \\
\hline HAMY & 0.45 & 0.45 & 0.94 \\
\hline LOINY1 & 0.23 & 0.39 & 0.95 \\
\hline BELY1 & 0.33 & 0.31 & 0.96 \\
\hline SRIBY & 0.38 & 0.32 & 0.89 \\
\hline PICNY & 0.31 & 0.30 & 0.93 \\
\hline BUTTY & 0.20 & 0.15 & 0.80 \\
\hline PRIMY & 0.20 & 0.20 & 0.91 \\
\hline
\end{tabular}

${ }^{1} \mathrm{LD}=$ Loin depth $; \mathrm{FD}=$ Fat depth $;$ CADG $=$ Carcass average daily gain; $\mathrm{IMF}=$ Intramuscular fat percent, MINA $=$ Minolta $\mathrm{a}^{*}$, MINB $=$ Minolta $b^{*}$, MINL $=$ Minolta $L^{*}, \mathrm{PH}=$ Ultimate $\mathrm{pH}$; SCOL $=$ Subjective color score; SMARB $=$ Subjective marbling score; SFIRM = Subjective firmness score; SSF $=$ Slice shear force, HAM = Ham weight; LOIN1 = Loin weight; BEL1 = Belly weight; SRIB = Spare rib weight, PICN = Picnic weight; BUTT = Butt weight; HCW $=$ Hot carcass weight; HAMY $=$ Ham yield; LOINY1 $=$ Loin yield; BELY1 = Belly yield; SRIBY $=$ Spare rib yield PICNY $=$ Picnic yield; BUTTY $=$ Butt yield; PRIMY $=$ Primal yield

*Significant correlations are highlighted in bold.

composition traits. The genetic correlations of meat quality and carcass composition traits with growth traits ranged from moderate to high in both directions. The genetic parameter estimates indicated that a multitrait approach should be considered for selection programs aimed at carcass quality and composition in commercial crossbred swine population. Although there was general opinion that selection for growth traits decreased the pork quality, we have shown here that growth traits, namely, CADG and
LD, did not deteriorate the pork quality. In addition, fat depth has both favorable and unfavorable relationships with meat quality traits. Hence, caution should be taken while selecting against fat depth. Selection for CADG will improve the primal weight. Primal yields could be improved by selection for growth traits with caution due to varied relationship. Identification of sex-specific genetic parameter on some traits indicated the advantage of selection of male and female separately for those traits in crossbred swine. Estimated parameters provide a reference value to establish the efficient breeding program that focuses on meat quality in United States.

\section{SUPPLEMENTARY DATA}

Supplementary data are available at Journal of Animal Science online.

\section{ETHICS APPROVAL AND CONSENT TO PARTICIPATE}

Animal welfare approval was not needed for this study because all data came from animals raised in commercial facilities under routine practices.

Conflict of interest statement. None declared.

\section{LITERATURE CITED}

Brewer, M. S., and F. K. McKeith. 1999. Consumer-rated quality characteristics as related to purchase intent of fresh pork. J. Food Sci. 64(1):171-174. doi:10.1111/j.1365-2621.1999. tb09885.X

Brewer, M. S., L. G. Zhu, and F. K. McKeith. 2001. Marbling effects on quality characteristics of pork loin chops: consumer purchase intent, visual and sensory characteristics. Meat Sci. 59:153-163. doi: 10.1016/S0309-1740(01)00065-1

Cabling, M. M., H. S. Kang, B. M. Lopez, M. Jang, H. S. Kim, K. C. Nam, J. G. Choi, and K. S. Seo. 2015. Estimation of genetic associations between production and meat quality traits in duroc pigs. Asian-Australas. J. Anim. Sci. 28:1061-1065. doi:10.5713/ajas.14.0783

Cameron, N. D. 1990. Genetic and phenotypic parameters for carcass traits, meat and eating quality traits in pigs. Livest. Prod. Sci. 26:119-135. doi:10.1016/0301-6226(90)90061-A

Cannon, J. E., J. B. Morgan, J. Heavner, F. K. Mckeith, G. C. Smith, and D. L. Meeker. 1995. Pork quality audit: A review of the factors influencing pork quality. J. Muscle Food. 6:369-402.

Christensen, O. F., A. Legarra, M. S. Lund, and G. Su. 2015. Genetic evaluation for three-way crossbreeding. Genet. Sel. Evol. 47:98. doi:10.1186/s12711-015-0177-6

Ciobanu, D., S. M. Lonergan, and E. J. Huff-Lonergan. 2011. Genetics of meat quality and carcass traits. In: Rothschild, M. F., and Rubinsky, A., editors. The genetics of the pigs. New York: CAB Int. p. 355-389.

Clutter, A. C. 2011. Genetics of performance traits. In: Rothschild, M. F., and Rubinsky, A., editors. The Genetics of Pigs. New York: CAB Int. p. 325-354. 
Clutter, A. C, and E. W. Brascamp. 1998. Genetics of performance traits. In: Rothschild MF, and Rubinsky A., editors. The Genetics of the Pig. Wallingford, United Kingdom: CAB Int. p. 427-462.

De Campos, C. F., M. S. Lopes, F. F. e Silva, R. Veroneze, E. F. Knol, P. S. Lopes, and S. E. F. Guimaraes. 2015. Genomic selection for boar tint compounds and carcass traits in a commercial pig population. Livest. Sci. 174:10 17. doi: 10.1016/j.livsci.2015.01.018

De Vries, A. G., P. G. van der Wal, T. Long, G. Eikelenboom, and J. W. M. Merks. 1994. Genetic parameters of pork quality and production traits in Yorkshire populations. Livest. Prod. Sci. 40:277-289. doi: 10.1016/0301-6226(94)90095-7

Dransfield, E., T. M. Ngapo, N. A. Nielsen, L. Bredahl, P. O. Sjödén, M. Magnusson, M. M. Campo, and G. R. Nute. 2005. Consumer choice and suggested price for pork as influenced by its appearance, taste and information concerning country of origin and organic pig production. Meat Sci. 69:61-70. doi:10.1016/j. meatsci.2004.06.006

Ducos, A, J. P. Bidanel, V. Ducrocq, D. Biochard, and E. Groeneveld. 1993. Multivariate restricted maximum likelihood estimation of genetic parameters for growth, carcass and meat quality traits in French Large white and French Landrace pigs. Genet. Sel. Evol. 25:475-493. doi: 10.1186/1297-9686-25-5-475

Forni, S., I. Aguilar, and I. Misztal. 2011. Different genomic relationship matrices for single-step analysis using phenotypic, pedigree and genomic information. Genet. Sel. Evol. 43:1. doi:10.1186/1297-9686-43-1

Franco, D., J. A. Vaquezand, and J. M. Lorenzo. 2014. Growth performance, carcass and meat quality of Celta pig crossbred with Duroc and Landrance genotypes. Meat Sci. 96:195-202. doi: 10.1016/j.meatsci.2013.06.024

Gilbert, H., J. P. Bidanel, J. Gruand, J. C. Caritez, Y. Billon, P. Guillouet, H. Lagant, J. Noblet, and P. Sellier. 2007. Genetic parameters for residual feed intake in growing pigs, with emphasis on genetic relationships with carcass and meat quality traits. J. Anim. Sci. 85:3182-3188. doi:10.2527/jas.2006-590

Gjerlaug-Enger, E., L. Aass, J. Odegård, and O. Vangen. 2010. Genetic parameters of meat quality traits in two pig breeds measured by rapid methods. Animal 4:1832-1843. doi:10.1017/S175173111000114X

Hermesch, S., B. G. Luxford, and H. U. Graser. 2000a. Genetic parameters for lean meat yield, meat quality, reproduction and feed efficiency traits for Australian pigs 2. Genetic relationships between production, carcass and meat quality traits. Livest. Prod. Sci. 65:249-259. doi:10.1016/ S0301-6226(00)00151-2

Hermesch, S., B. G. Luxford, H. U. Graser. 2000b. Genetic parameters for lean meat yield, meat quality, reproduction and feed efficiency traits for Australian pigs 3. Genetic parameters for reproduction traits and genetic correlations with production, carcass and meat quality traits. Livest. Prod. Sci. 65:261-270. doi:10.1016/ S0301-6226(00)00152-4

Hicks, C., F. Tsutomu, and A. P. Schinckel. 1998. Estimates of genetic parameters for daily gain and carcass traits for Japanese large white swine. http://www.ansc.purdue.edu/ swine/swineday/sday98/psd27-98.htm (Accessed 1 August 2018.)
Hovenier, R., E. Kanis, T. V. Asseldonk, and N. G. Westerink. 1992. Genetic parameters of pig meat quality traits in a halothane negative population. Livest. Prod. Sci. 32:309321. doi: 10.1016/0301-6226(92)90002-L

Jiao, S., C. Maltecca, K. A. Gray, and J. P. Cassady. 2014. Feed intake, average daily gain, feed efficiency, and real-time ultrasound traits in duroc pigs: I. Genetic parameter estimation and accuracy of genomic prediction. J. Anim. Sci. 92:2377-2386. doi:10.2527/jas.2013-7338

Lattore, M. A., C. Pomar, L. Faucitano, C. Gariepy, and S. Methot. 2008. The relationship within and between production performance and meat quality characteristics in pigs from three different genetic lines. Livest. Sci. 115 (2-3):258-267. doi: 10.1016/j.livsci.2007.08.013

Lee, J. H., K. D. Song, H. K. Lee, K. H. Cho, H. C. Park, and K. D. Park. 2015. Genetic parameters of reproductive and meat quality traits in korean berkshire pigs. Asian-Australas. J. Anim. Sci. 28:1388-1393. doi:10.5713/ ajas. 15.0097

Legarra, A., I. Aguilar, and I. Misztal. 2009. A relationship matrix including full pedigree and genomic information. J. Dairy Sci. 92:4656-4663. doi:10.3168/jds.2009-2061

Lei, H., C. Zhang, C. Li, G. S. Plastow, and H. L. Bruce. 2018. Efficacy of genetic parameter estimation of pork loin quality of crossbred commercial pigs using technological quality measurements of frozen and unfrozen product. Can. J. Anim. Sci. 98:453-462. doi:10.1139/ cjas-2017-0154.

Lo, L. L., D. G. McLaren, F. K. McKeith, R. L. Fernando, and J. Novakofski. 1992. Genetic analyses of growth, real-time ultrasound, carcass, and pork quality traits in duroc and landrace pigs: II. Heritabilities and correlations. J. Anim. Sci. 70:2387-2396. doi:10.2527/1992.7082387x

Lonergan, S. M., K. J. Stalder, E. Huff-Lonergan, T. J. Knight, R. N. Goodwin, K. J. Prusa, and D. C. Beitz. 2007. Influence of lipid content on pork sensory quality within ph classification. J. Anim. Sci. 85:1074-1079. doi:10.2527/ jas.2006-413

Maignel, L., J. P. Daigle, C. Gariepy, D. Wilson, and B. Sullivan. 2010. Prediction of intramuscular far in live pigs using ultrasound technology and potential use in selection. http://www.wcgalp.org/system/files/proceedings/2010/ prediction-intramuscular-fat-live-pigs-using-ultrasoundtechnology-and-potential-use-selection.pdf (Accessed 12 August 2018.)

Mancini, R. A., and M. C. Hunt. 2005. Current research in meat color. Meat Sci. 71:100-121. doi:10.1016/j. meatsci.2005.03.003

Miar, Y., G. S. Plastow, S. S. Moore, G. Manafiazar, P. Charagu, R. A. Kemp, B. Van Haandel, A. E. Huisman, C. Y. Zhang, R. M. McKay, et al. 2014a. Genetic and phenotypic parameters for carcass and meat quality traits in commercial crossbred pigs. J. Anim. Sci. 92:2869-2884. doi:10.2527/jas.2014-7685

Miar, Y., G. Plastow, H. Bruce, S. Moore, G. Manafiazar, R. Kemp, P. Charagu, A. Huisman, B. van Haandel, C. Zhang, et al. 2014b. Genetic and phenotypic correlations between performance traits with meat quality and carcass characteristics in commercial crossbred pigs. PLoS One. 9:e110105. doi:10.1371/journal.pone.0110105.

Misztal, I., T. Shogo, D. Lourenco, I. Aguilar, A. Legarra, and Z. Vitezica. 2015. Manual for BLUPF90 family of 
programs; 2015. http://nce.ads.uga.edu/wiki/lib/exe/fetch. php?media=blupf90_all2.pdf (Accessed 1 March 2019.)

National Pork Producers Council (NPPC). 1999. Official color and marbling standards. NPPC, Des Moines, IA.

Newcom, D. W., T. J. Baas, J. W. Mabry, and R. N. Goodwin. 2002. Genetic parameters for pork carcass components. J. Anim. Sci. 80:3099-3106. doi:10.2527/2002.80123099x

Newcom, D. W., T. J. Baas, K. J. Stalder, and C. R. Schwab. 2005. Comparison of three models to estimate breeding values for percentage of loin intramuscular fat in duroc swine. J. Anim. Sci. 83:750-756. doi:10.2527/2005.834750x

Ober, C., D. A. Loisel, and Y. Gilad. 2008. Sex-specific genetic architecture of human disease. Nat. Rev. Genet. 9:911922. doi:10.1038/nrg2415

Sargolzaei, M., J. P. Chesnais, and F. S. Schenkel. 2014. A new approach for efficient genotype imputation using information from relatives. BMC Genomics 15:478. doi:10.1186/1471-2164-15-478

Sellier, P. 1998. Genetics of meat and carcass traits. In: Rothschild M. F., and Rubinsky A., editors. The Genetics of the Pig. CAB Int, Wallingford, United Kingdom. p. 463-510.

Serrano, M. P., D. G. Valencia, A. Fuentetaja, R. Lazaro, and G. G. Mateos. 2009. Influence of feed restriction and sex on growth performance and carcass and meat quality of Iberian pigs reared indoors. J. Anim. Sci. 89:1676-1685. doi: 10.2527/jas.2008-0989.

Sevillano, C. A., J. Vandenplas, J. W. M. Bastiaansen, R. Bergsma, and M. P. L. Calus. 2017. Genomic evaluation for a three-way crossbreeding system considering breedof-origin of alleles. Genet. Sel. Evol. 49:75. doi:10.1186/ s12711-017-0350-1

Singh, K. P., R. R. Mishra, R. Singh, and A. P. Chaudhary. 2001. Heritability estimates for growth and carcass traits in landrace pigs. Indian J. Anim. Res. 35(Suppl 2): 138-140.

Sonenson, A. K., K. H. de Greef, and T. H. E. Meuwissen. 1998. Genetic parameters and trends of meat quality, carcass composition and performance traits in two selected lines of large white pigs. Livest. Prod. Sci. 57:23-32. doi: 10.1016/S0301-6226(98)00163-8
Suzuki, K., M. Irie, H. Kadowaki, T. Shibata, M. Kumagai, and A. Nishida. 2005. Genetic parameter estimates of meat quality traits in duroc pigs selected for average daily gain, longissimus muscle area, backfat thickness, and intramuscular fat content. J. Anim. Sci. 83:2058-2065. doi: $10.2527 / 2005.8392058 \mathrm{x}$

VanRaden, P. M. 2008. Efficient methods to compute genomic predictions. J. Dairy Sci. 91:4414 4423. doi:10.3168/ jds.2007-0980

Virgili, R., M. Degni, C. Schivazappa, V. Faeti, E. Poletti, G. Marchetto. 2003. Effect of age at slaughter on carcass traits and meat quality of italian heavy pigs. J. Anim. Sci. 81:2448-2456. doi:10.2527/2003.81102448x

van der Werf, J. 2013. Genomic selection in animal breeding programs. In: C. Gondro, J. van der Werf, B. Hayes, editors. Methods Mol. Biology (Methods and protocols). Humana Press, Totowa, NJ, vol. 1019. p. 543-61.

van Wijk, H. J., D. J. Arts, J. O. Matthews, M. Webster, B. J. Ducro, and E. F. Knol. 2005. Genetic parameters for carcass composition and pork quality estimated in a commercial production chain. J. Anim. Sci. 83:324-333. doi:1 $0.2527 / 2005.832324 x$.

Walters, C. L. 1975. Meat color: the importance of haem chemistry. In: D. L. A. Cole, R. A. Lawrie, editors. Meat. AVI Publishing Co, West port, CT. p.385-401.

Wang, S., N. Yehya, E. E. Schadt, H. Wang, T. A. Drake, and A. J. Lusis. 2006. Genetic and genomic analysis of a fat mass trait with complex inheritance reveals marked sex specificity. Plos Genet. 2:e15. doi:10.1371/journal.pgen.0020015

Wilson, K. B., M. F. Overholt, E. K. Hogan, C. Schwab, C. M. Shull, M. Ellis, N. S. Grohmann, A. C. Dilger, and D. D. Boler. 2016. Predicting pork loin chop yield using carcass and loin characteristics. J. Anim. Sci. 94:49034910. doi:10.2527/jas.2016-0610

Wilson, K. B., M. F. Overholt, C. M. Shull, C. Schwab, A. C. Dilger, and D. D. Boler. 2017. The effects of instrumental color and extractable lipid content on sensory characteristics of pork loin chops cooked to a mediumrare degree of doneness. J. Anim. Sci. 95:2052-2060. doi: $10.2527 /$ jas. 2016.1313 